\title{
What Is an Organizational Strategic Decision?
}

\begin{abstract}
Strategy is the overall decision-making on three major questions: where are we going? What are the main obstacles and challenges (or major problems) we face on the way to development goals? What kind of guiding ideology should we use to deal with the major problems in development?
\end{abstract}

\subsection{Introduction}

The word "strategy" emerged from the war. In ancient times, wars were common. For example, Country A (hereinafter referred to as A) attempts to expand its territory by conquering Country B (hereinafter referred to as B) which is normally the weaker one, so A needs a strategy for success, a goal-oriented one, which means the goal calls for the strategy.

Under the threat of A, B has to resist the aggression of A with a strategy, a problem-oriented one, which means the threat demands for the strategy, so the strategy originated from serving the goal or the key issue.

Let us look at B first. B is facing an aggression from a more powerful enemy than it is. Any country will resist when it is invaded by foreign aggression. B will set the goal to protect its territory and expel the aggressor out of the country. How the weak one could get the upper hand over the strong? Or what ways or guiding principles should the monarch of B take to defeat the aggressors? This is something the $\mathrm{B}$ monarch must consider, which needs a basic guideline or principle, and is conventionally called strategy. As for B, the strategic approach of defeating the foreign enemy has everything to do with the problem (of a stronger counterpart) and the goal (of keeping the aggressors out of its own territory). If the monarch of B is 
muddleheaded, he or she might not have faith in expelling the aggressors and will set a goal of tolerating the enemy at large or even allowing them to build a puppet government. With the goal, he or she will not take any measures to resist aggression or even help the invaders to build a governing body.

In this case, we can see that in the problem-oriented strategy of $\mathrm{B}$, there are three decisions that the monarch of $\mathrm{B}$ needs to make. One is the decision on identifying the nature of the key problem. The problem in the case is clear that is my country is invaded and my enemy is stronger than me, or my major problem it the aggression from the more powerful enemy (decision related with element of key issue). Second is the decision on setting up the goal. In this case, both goals of blocking the invaders from getting in and allowing them to get inside are possible. The monarch of $\mathrm{B}$ has to determine which goal to take (decision related with element of long-term goal). Third is the decision on what or which general guiding principles ought to take in order to resolve the problem of the aggression from the more powerful enemy (decision related with element of guideline). The whole set of the three decisions indeed is the reflection of the three fundamental elements of the strategy concept which we elaborate in early chapter.

Let us look back at A. If it has a strategic goal of expanding territory and occupying $\mathrm{B}$, if $\mathrm{A}$ encountered violent resistance from $\mathrm{B}$, which is a problem came up, it will need an overall guideline to deal with B's resistance and achieve the goal of aggression. If $\mathrm{B}$ does not resist, the problem $\mathrm{A}$ faces will change fundamentally from how to deal with B's aggression to how to rule B, and for governing B, A needs a new strategy to turn B into its colony.

Similarly, the goal-oriented strategy for A also has three decisions: first is the decision of determining the long-term goal. In this case, A made the decision on occupying B and expanding territory (decision on element of long-term goal). Second is the decision on defining the nature of the major problem. In this case, the problem could be the resistance of a weak country; or how to let the civilian population of $\mathrm{B}$ complying the rule of A (decision on element of major issues). Third is the decision on formulating general principles of settling the major issues (decision on element of guideline). Also, the strategic decision of A includes the whole set of the three sub-decisions that are related to the three fundamental elements of the strategy concept.

We have introduced the strategic decisions related to the three elements of goal-oriented and problem-oriented strategies in the war, which also exists in companies. Let us look at two examples that we have familiar with in early chapter.

In 2002, when Alibaba was planning to enter the personal online trading platform industry, the company needed to make a strategic decision. ${ }^{1}$ It is a goal oriented strategy and has three sub-decisions. One decision is to provide answer to the question of "what is my goal of entering into personal online trading platform industry"? eBay, a well know multinational company in the industry already had about $80 \%$ of the market share at that time. We know that even under this

\footnotetext{
${ }^{1}$ For Jack Ma, it is a strategic decision about how to compete, or what we normally call as competitive strategy, or generic strategy.
} 
circumstance, Jack Ma's decision on "what is my goal" was to gain market share from eBay and be success (a decision about development goal). To compete with eBay, Taobao needed to make another decision on identifying what would be the biggest problem we have in competing with eBay. Jack Ma attributed the problem as "what kind of online trading platform would be favored by Chinese customers" (decision related with major issue in competition and of company's development). The third decision is about the general ideology to guild solving the problems identified in the second decision. Jack Ma adopted hybrid thought (decision concerning the guideline to the solution of main problems). We can see that similar to military examples illustrated early, the strategic decision for Jack Ma also has three sub-decisions. They are integrated and related to each other.

In 2006, Svenska Kullager-Fabriken (hereinafter referred to as SKF), a world-leader in design, manufacture, and sales of bearings, was under the threat of the industry changing into a low-end market with cheap product for common usage. The company needed a strategy to respond to the challenges from the market. The strategy is problem oriented. Again, the executives of SKF needed to make three sub-decisions. The first was to determine what problem was. As the strategy was problem oriented, the problem was emerged from the market. That was the industry was changing into a low-end market with cheap product for common usage and how do we do with it (major development issue). The answer the question "how" needs to provide strategic solution to the problem. The choices of the solutions could be multiple, to plays up to the low-end market or not. SKF realized that if the company caters to trends of competition, they are not likely to maintain their market share and profitability as their costs are higher than low-end providers are. The company made the decision to maintain the market share on the premise of maintaining the company's advantages (decision on goal). As the company had technological superiority in the industry, it choose to be different from low-end market with rapid response to customer needs (decision on guideline). SKF set up five global technological plate forms to link the company's worldwide 3000 engineers in order to react to market needs quickly.

We can see from above examples that on the general consideration of all kinds of practical strategies in companies, a strategic decision is composed of three sub-decisions. They are "decision on the development goal", "decision on the major development issue", and "decision on the overall guiding principle" whether it is a goal-oriented strategy or a problem-oriented one. The business strategy is an integrated overall design making concerning the three elements of the strategy concept.

Now let us look at the specific meanings of the three sub-decisions relating to the three elements in business strategy. 


\subsection{Strategic Decision}

\section{(1) Decision on setting up future development direction}

How will the company develop in the future? Where will it go? One task of the strategic decision is to set up the directions or development goals, or long-term goals for the company. The decision-makers need to point out the direction for the development of the company in the next period, say next 5 to 10 years.

Under different circumstances and specific industrial characteristics, the development goals differ among companies. In a rapidly developing economic environment, there are more opportunities than treats. Thus, there will be more goal-oriented strategies than problem-oriented ones.

In the goal-oriented strategy, the long-term goal is ambitions and expectations of the future from the decision-maker with ideals and dreams who makes the decisions with his values and judgments. Normally, the strategic goal has a long-term nature, which takes years of efforts to achieve. The decision on setting up the strategic goal has to be made after overall considerations on the company characteristics and industrial environment of the company.

In general, most companies set their development goals as increasing profits or returns such as market shares goal and financial performance goal according to their own conditions. In Porter's point of view, the development goal on the business level is mainly on getting the competitive advantage and outperforming other competitors. While on the corporation level, the decision-maker needs to decide whether or not they should enter a new area or new trade, and whether or not they should expand business in new regions. Therefore, the long-term goals are different on the business level and group corporation level (See Table 4.1).

Table 4.1 Development goal (business level and group corporation level)

\begin{tabular}{l|l}
\hline & Development goal \\
\hline Business & Enhance competitiveness \\
level & To distinguish yours ( products and services) with competitors (differentiated) \\
Put competitors at the disadvantage situation(e.g. through market or \\
non-market instruments) \\
Improve market position and competitiveness (e.g. become a domestic leader \\
or the industry leader) \\
Increase or maintain market share \\
Improve financial performances \\
Improve development capabilities for new products \\
Sustainable development, environment protection goals \\
etc.
\end{tabular}


We can see from above that the specifics about the long-term goals are mostly qualitative goals (like increasing R\&D capabilities, enhancing competitiveness, entering into new markets, entering into high-end market, etc.). Sometimes the goals can be a multi-purpose one, or a combined goal, like "entering into a new market" and "improving performances", or "improving development capabilities for new products" and "increasing market share". Generally, the long-term goals are different from the financial ones in strategic decisions: the former ones are for future directions and the latter are for profitability goals in the directions.

For problem-oriented strategic decision, although there is (are) major problem(s) in the development of the company, and the company is seeking a solution to the problem. Goal setting is still an important part in the strategic decisions, as different goal will lead to different strategic solutions. The goal is closely related to the problems they are facing as well as their own resources and capabilities. Generally speaking, the goal is mainly on solving the problem partially or for all. Like Kodak, when suffering from the impact of digital camera products from 2002 to 2005, it took loss reduction as a goal. While for SKF in 2006, facing the impact of the low-end market, it rose up to the challenge and adopted the differentiated strategy with strong technology to secure its competitive advantage and profit.

What's worth mentioning is that the decisions about the long-term goals are often decided within a time range, i.e. during how long (e.g. in 5 years, 8 years, 10 years, or even 20 years) time should the company have to achieve the goals. It can be divided into some time stages. For instance, a 6-year goal could be divided into two stages, achieving initial goal within 3 years, and reaching final goal within 6 years.

We have seen the strategic goal of Taobao in the above example. Mr. Li Shufu, the founder of Geely, had the ambition to enter the high-end market of automotive manufacturing (development goal) in 2002, which took ten years to accomplish. Now Taobao and Geely all realized their strategic goals, then these were also the dreams and expectations of Jack Ma and Li Shufu.

To set up strategic goal is an indispensable part of the strategic decisions. It reflects a company vision in a certain period, and is the expected result that the enterprise wishes to achieve in a certain stage. Compared with objectives in daily operations, corporate major development goals feature in coherency, long-term, separable and challenging, etc.

A strategic decision, which lacks a goal, will be undirected. In addition, the wrong goal setting will lead to not only big directional mistakes in the development of the company, but also huge financial loss. Knowing yourself and your competitors, especially, correct judgment of the development situation of the industry are the keys for proper goal setting.

The decisions of the strategic goals can be influenced by factors as follows.

First, the industry development stage where the company business lies. As we all know, the life cycle of an industry can be divided into four stages. Sometimes for one industry, different markets will not be in the same stage. For example, in the 1980s when the automotive industry in China was initiated, there was already a mature market in Europe and the United States. Furthermore, different products in 
the same industry will experience different stages, for example, the mobile phone has evolved from cellular phones, keyboard phones, to different kinds of smart phones updating occasionally. Each is going through different stages. Here we will narrow the product in one industry or service in one market and see what are the differences in the corporate strategic goals.

In the early stages of the development of an industry, the technology has initially started, and there are few competitors and the products are expensive but normally with poor quality. The market favors the seller because of low (not much) supply, and the primary goal of the company is to obtain technologies and produce for sell. The second stage is the growth period when the industry develops fast and technology remains stable. With the increasing numbers of competitors, that of the users grow rapidly as well. In the initial period of the second stage, the development goal of companies normally lies in increasing production capacity and sales channels as well as expanding markets. In the later period of the growth stage, the industrial demand is still rising. However, since there are a large number of competitors, the production scale becomes larger, and consumers are more experienced with more knowledge in products. Therefore, from the perspective of competition, the main goal of the company is to produce better competitive products to attract customers. The third stage is the maturity period when the market demand for products and services was decreasing, resulting in fiercer competitions. Some companies will withdraw from the market and the rest who are still in the industry will take every effort to reduce costs for profit retain when the demand declines. In the fourth stage, the market demand drops dramatically, and most companies in the industry will withdraw its business from the market. The company's development goal is to look for emerging markets.

The second factor that influences decision-making in setting up corporate strategic goals is the competitive strategy of the competitors in the same industry. The attitude and strategy of the competitors have great impact on the corporate strategy making. Apple Inc. had a strategic intent to offer better mobile phone products to the market than competitors. In 2007, Apple launched iPhone, a technology product that combines iPod and mobile phones. It is also a network tool and a mobile computer. Apple's new products received great favor of the market. Motorola, and Ericsson were left behind. Therefore, you need to monitor your industry and your competitors in terms of their competitive strategies and make a corresponding strategy.

The third factor is the company's own resource and capability, and the goal that was achieved in the past. According to Barney's resource based view, corporate strategy should be determined by its resources and capabilities, that is, the strength decides the goal. The implementation of the strategic goal generally needs to invest in funds and human resources. The financial strength, technical strength, management ability, and previous experience of the company have an important impact on the formulation of the company's strategic objectives. Some big companies with strong strength play the leading role in the industry. Its strategic objective is different from that of the relatively weak companies in the industry. We know that Mr. Wang Jianlin, a Chinese commercial real estate developer, has a well-known sentence. I first set a small goal that I can achieve, for example, 1 hundred million (RMB). One hundred million is a small goal for Mr. Wang Jianlin, but it's a big 
goal for many small companies. In addition, the previous experience of the company has an important impact on the development of new strategic goals. In the early 90 s, when Geely wanted to enter the car industry. The company is a novice in the industry and has no industry experience. Hence, the company's initial goal was to make the car and to get the license from government. Some companies have rich experience in $\mathrm{M} \& \mathrm{~A}$ or transnational management, and they will set a goal concerning the expansion of scale.

The fourth factor is the values, business philosophy and judgement of corporate decision-makers, whose ways of thinking and personalities greatly influence corporate strategic goal making.

We have mentioned about an important strategic decision above, which is to define directions for organization development, or the strategic goals. As far as goal-oriented strategy goals, there is no need for a strategy if there does not exist a long-term goal. Whether it is a goal-oriented strategy or problem-oriented strategy, one of the primary task for setting up a strategy is to make a long-term goal.

\section{(2) Decision on identifying firm "major development issue"}

What are the major difficulties and obstacles of organization development? Another important mission of strategic decision-making is the identification of important issues laying ahead in the path to achieve the organization development goals.

Organization major development issues, which can also be called strategic issues or development problem, are the key obstacles and challenges encountered in organization development. When making a strategy, decision-makers have to identify and conceptualize the key problems. Conceptualization is to summarize and extract the quintessence that can reflect the real situations. For example, in the early period of the Agrarian Revolution in China, Chairman Mao Zedong conceptualized the strategic problem as "against the stronger enemy" to epitomize the great disparity in strength between the Communist Party and Kuomintang (hereinafter referred to KMT). This decision also has another meaning, which is fighting. In the case of Taobao we mentioned in the previous chapter, Taobao needs to identify the major competition problems it encounters. Jack Ma summed up as following: "We have a big competitor" and "What kind of platform could be appeal to customer and would be more competitive than eBay". This decision has two meanings. One is that I recognize the strength in the other side. Another meaning is fight reflected in gain competitive advantage in the eyes of customers.

In the problem-oriented strategy, the major development issue owes to competition within the industry, external environmental changes and internal operation problems, which can be summarized as below (see Table 4.2).

Whether it is a goal-oriented strategy or a problem-oriented strategy, major problems in company development will block its way to achieve long-term goals, which require the high-level decision-maker to identify and get things under control.

Sometimes there are serious problems in company business and operations, such as declining performances or losses for years, when high-level managers realized the seriousness of the problems in company's development and came up with a 
Table 4.2 Origin of Major Development Issues
Development issues arising from industry competition

(1) Better product alternatives from competitors with improved functions and cheaper prices

(2) Better products or services with same quality and cheaper price launched on the market by competitors

(3) Prices of key raw materials and core parts raised while sales prices decrease due to industrial competition

(4) Business model changes in the main competitors leaving low value-added business to those who do not realize the industrial changes and modify their business models

(5) Products from the suppliers are in an oligopoly market controlled by main competitors within the industry

(6) Others

Development issues due to external environmental changes

(1) Product demand declines owing to slow growth of regional economy

(2) Consumer demand restrained by industry policies from the local government

(3) Others

Development issues from in-house changes

(1) Senior management (or decision-makers) fails to effectively identify the above threats externally or incapable of making any efficacious countermeasures

(2) Key management employees leave when normative management regimes have yet to take shape

(3) Key R\&D employees leave

(4) Key sales employees leave

(5) Business rely on few customers and suppliers in long-term

(6) Others

corresponding reaction. From time to time, some high-level managers will forecast possible major issues in organization development with everything they get their hands on and bring up strategic resolutions. Hence, for problem-oriented strategy, if there is no major development issues, strategy will not be needed.

The identification of the major issues in organization development path is also important for goal-oriented strategy. Because after the development goal is made, the guideline or strategic approach has to be in place to secure accomplishment of the goal. The guideline is designed or discovered specifically for resolving major organization development issues. Therefore, the discovery and identification of the crux is a key work of strategic decision-makings. For example, when Taobao planned to enter into online personal platform business and win market shares from eBay, the key hinges on how to compete with eBay and how to win customer's affection in its services. In 2002, Geely set up the goal to enter into high-end market; however, it was faced with dual development difficulties of lacking both high-end automobile technology and sufficient capital.

As a result, whether it is problem-oriented strategy or goal-oriented one, high-level managers have to identify major issues in organization development, which is an important work in strategic decision-makings. The lack of the 
identification of major development problems will lead to muddled strategy. Indeed, correctly identifying and defining the major core issues that actually impede the development of the company will lay a good foundation for the third (or next) decisions of the strategy.

\section{(3) Decision on setting up the guidelines for resolving major issues}

If the strategic problem cannot be solved, the organization development goal will not be realized. Therefore, after the major issues in organization development are identified, senior managers have to come up with ideas from a high level in resolving the issues, or bring up overall ideology for guiding the resolution of the strategic issues. The overall ideology can be a general guideline manifested in basic philosophy or principle.

As we have mentioned above, Taobao with its competitive mind of value for money and Geely with its technology and brand being acquired externally. Both of them have brought up a general idea or principle for solutions to their problems.

Therefore, the third important task of strategic decision-makings is to bring up a general guiding ideology for resolving major issues encountered in corporate development. As a matter of fact, the strategy conventionally means the general guiding ideology, which can also be called strategic approach.

Strategic approach is different from what we have understood in the general way. It is a guidance representing the embodiment of the policy maker's thought. Let us take an example from the daily life to illustrate the difference between strategic approach and daily or ordinary resolution.

Let us assume that here is a woman surnamed Zhang who lives in Shanghai and just got married. She has to be transferred to work in Beijing for one year. So how do we solve the problem of the love-sickness of the newlywed couple? As we known, there are many ways to solve the problem, Zhang can come back to see her husband in Shanghai on business trip or on weekends. Without the guidance of the overall principle, each time Zhang comes back will be seen as the routine resolution for love-sickness. What will be the strategic approach? When Zhang take an overall view, like she thinks the income of the family isn't that high but she still hopes to go home regularly to see her husband, she will make the plan of going back to Shanghai by high-speed rail once every two weeks. This plan embodies a basic philosophy of realizing the goal of going back home regularly without a high expenditure, which can be seen as a strategic approach with a philosophy for guidance.

There are multiple strategic approaches to resolve major organization development issues. The final decision on the selection of strategic approach not only lies in the values, judgments on corporate resources and capabilities (like technologies and capital) of the decision-makers, but also in their judgments about the external environment and future development trends. This also shows why in strategic management books, there are chapters on the analysis of the company's internal resources and capabilities, and on the analysis of the company's external situation, all of which are intended to help decision-makers master key information. As a 
company's strategic decision maker, you shall always pay attention to the company's internal and external key information and their trend changes.

Geely can develop the high-end automotive by itself, but it chose to acquire Volvo and enter the market much faster and enjoys high-end automotive brand and technology at the same time. Alibaba chose to provide much better and less expensive service than eBay (i.e. the strategic approach of more for money), and won customer's favor to get competitive advantage. While SKF took the differentiated strategic approach to distinguish itself from the low-end market competitors to avoid competitions. You will see from the examples that no matter the goal-oriented strategy like Geely and Taobao, or the problem-oriented ones such as SKF, they all have clear guidelines on resolving the major development issues. The guidelines are closely related to the development goals and the major development problems of companies.

\section{(4) Strategy-integrated decision of three sub-decisions}

Any comprehensive strategy is composed of three basic elements. They are long-term goal, major development issue, and general guideline for resolving major issue. The three elements are all closely connected and no one is dispensable to make a whole.

Actually, the three elements involve three core questions in strategic decision. A strategic decision is made up of three sub decisions related to the three elements, i.e. a complete strategy needs to answer three questions in a whole as follows.

- Development goal (defining company development directions): Where are we going?

- Development issue (identifying major issues and challenges): What are the biggest huddles and challenges we will (or have) encounter(ed) on the way of achieving development goals?

- Overall guideline (choosing the general ideology to solve development issues): What are the guiding philosophy that will help us to solve the major issues in our development?

Reviewing the strategies mentioned in Taobao, Geely, SKF and Kodak in the last chapter, we would have a clear picture of company strategic decisions on the three questions above (See Tables 4.3 and 4.4).

In Table 4.3, both decisions about future development goals of Jack $\mathrm{Ma}$ and $\mathrm{Li}$ Shufu implies their forecast of the future industrial development trend and confidence in future growth. Their identification of the key obstacles and problems, and full knowledge of their firms helped them found the key train of thoughts for problem solving.

Strategy in Table 4.4 is problem-oriented. The problems are emerged in competition. The general ideology for resolving the problems are closely related to the goals. In the example of SKF, if the top managers were deeply convinced that the industry would evolve into the common product, the future goals of the company 
Table 4.3 Goal-oriented Strategic Decisions (Examples)

\begin{tabular}{l|l|l}
\hline $\begin{array}{l}\text { Strategic Decision on } \\
\text { the } 3 \text { questions }\end{array}$ & Taobao & Geely \\
\hline $\begin{array}{l}\text { (Development goal) } \\
\text { Where are we going? }\end{array}$ & $\begin{array}{l}\text { We are going to enter the } \\
\text { personal online trading platform } \\
\text { successfully }\end{array}$ & $\begin{array}{l}\text { We are going to enter } \\
\text { high-end automotive market } \\
\text { successfully }\end{array}$ \\
\hline $\begin{array}{l}\text { (Development issues) } \\
\begin{array}{l}\text { What are the key issues } \\
\text { we are facing? }\end{array}\end{array}$ & $\begin{array}{l}\text { What kind of service platform } \\
\text { should we provide to be more } \\
\text { popular in China than eBay? }\end{array}$ & $\begin{array}{l}\text { How do we get technology } \\
\text { and money to get into the } \\
\text { high-end automotive market? }\end{array}$ \\
\hline $\begin{array}{l}\text { (Guideline) What are } \\
\text { the general ideology for } \\
\text { solving the problems? }\end{array}$ & $\begin{array}{l}\text { Designed and promoted much } \\
\text { cheaper (price is zero) with } \\
\text { better service platform (direct } \\
\text { communication channels and } \\
\text { addressed the problem of trust in } \\
\text { Chinese buyers and sellers) }\end{array}$ & $\begin{array}{l}\text { Market acquisition: acquiring } \\
\text { Volvo in 2009 with a } \\
\text { competitive price }\end{array}$ \\
\hline
\end{tabular}

Table 4.4 Problem-oriented strategic decisions (Examples)

\begin{tabular}{l|l|l}
\hline $\begin{array}{l}\text { Strategic Decision on } \\
\text { the } 3 \text { questions }\end{array}$ & SKF & Kodak \\
\hline $\begin{array}{l}\text { (Development issues) } \\
\text { What are the key }\end{array}$ & $\begin{array}{l}\text { Products in the low market will } \\
\text { drive the industry into making } \\
\text { general product }\end{array}$ & $\begin{array}{l}\text { How do we respond to the } \\
\text { impact of digital cameras } \\
\text { caused by company's declining } \\
\text { performance and losses? }\end{array}$ \\
\hline $\begin{array}{l}\text { (Development goals) } \\
\text { Where are we going? }\end{array}$ & $\begin{array}{l}\text { We need to keep the market } \\
\text { share without losing our } \\
\text { competitive edge }\end{array}$ & We have to cut losses \\
\hline $\begin{array}{l}\text { (Guideline) What are } \\
\text { the general ideology } \\
\text { for solving the } \\
\text { problems? }\end{array}$ & $\begin{array}{l}\text { We have to differentiate } \\
\text { ourselves with competitors in } \\
\text { the low-end market and be } \\
\text { specific (we will build five } \\
\text { technical "platforms" 3 which } \\
\text { will "connect" over 3000 } \\
\text { engineers to make quick } \\
\text { solutions on every product } \\
\text { development problem in design } \\
\text { and manufacturing) }\end{array}$ & $\begin{array}{l}\text { Reorganization and layoffs } \\
\text { (Established digital business } \\
\text { and successfully getting out of } \\
\text { some traditional business. } \\
\text { Closed 13 manufacturing plants } \\
\text { and 130 processing } \\
\text { laboratories. Laid off 47,000 } \\
\text { employees in total before 2011; } \\
\text { filed for bankruptcy protection } \\
\text { before 2012) }\end{array}$ \\
\hline
\end{tabular}

would not be "keeping the market share without losing competitive edge". Nor would there be an overall ideology of high differentiation.

From above we can see that the strategic decision is different from the daily ones. It is not a simple decision about the corporate development direction or long-term goals, but a decision on three major questions, which are closely connected. Only by integrating the three decisions can organization strategy avoid blankness and sheer abstraction. 
Let us have a look at a military example and see how the three sub-decisions are integrated to form a complete strategic decision. Figure 3.1 is the illustration of the military strategic decision of Chairman Mao and veteran proletarian revolutionaries during the early revolution of the Communist Party of China.

- This comprehensive strategy has three decisions. One is the identification or determination of the key development issue. It was "against the stronger enemy" (the box in the low left corner of the figure). This decision seems not like a decision, but it is a decision. This decision needs to determine the nature of the problem. Here it was defined as the enemy was stronger, or we were facing a strong enemy. The difference in the nature of the key development problem has a decisive impact on the decision of the general guideline. If the determination of the nature of the problem is far from the actual situation, we know what the consequences of strategic decision will be. In terms of business operations, a blurred picture could happen when decision makers do not know well of the industry and the organization.

The second decision is to set up the goal. It was "active defense". We see that even though the enemy was strong, in this strategic decision, the decision for goal was not escape. "Defense" means conserve the forces and avoid large-scale wars and unnecessary sacrifices. While "active" signifies fight against enemy. Hence, the decision on the "goal" was conserve the forces and meanwhile beat against the enemy. Again, we see the decision was clear and designated the direction.

How a weak me can fight against a strong enemy and at the same time to conserve the forces? The third decision concerns about the answers to the question of "how" in general sense. The decision in this case are the four sentences (known as 16-word policy in Chinese). The four sentences embody the essence of guerrilla warfare and provide guidance for the specific warfare.

In this strategic decision, it has three sub-decisions. You will find that without the decisions of actively defended goal on the top of the triangle and identification of the enemy (against a stronger enemy) in the lower left corner of the triangle, there will be no decision of the 16-word policy, which was concluded and extracted in the guerrilla wars and took into shape gradually. The decision of the overall guiding ideology is closely related to the decisions of goals and the major issues to complete in the triangle (Fig. 4.1).

\subsection{Making Strategic Decision Is Not an Easy Task}

Setting the right goals requires senior managers to have the correct forecasts for the future. Taking Taobao as an example, Jack Ma accurately predicted the development trend of e-commerce business in China. In Geely's case, Mr. Li precisely predicted demand trends for high-end cars in China. In 2004, Huawei decided to 


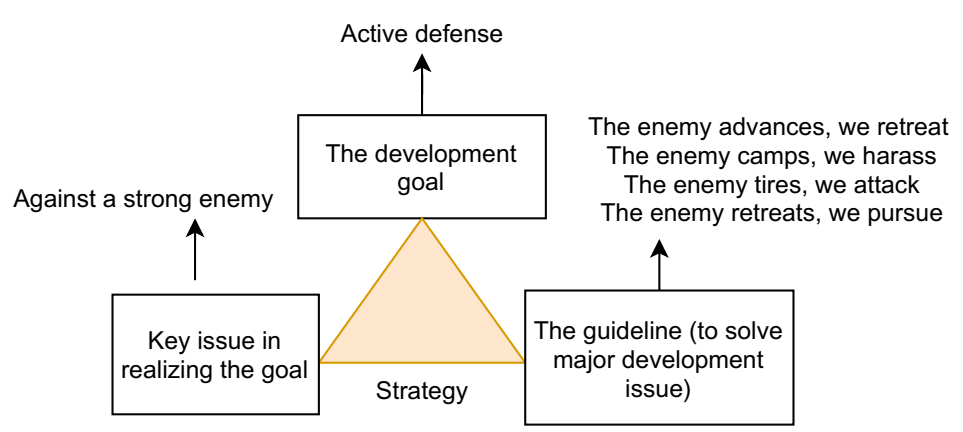

Fig. 4.1 The Three Elements of the active defense strategy of Mao Zedong

independently develop and produce chips. Chip research and development takes a long time and requires a huge investment. Many people could not understand the decision, as there were already professional chip manufacturers in the market. However, Huawei insisted on doing so. Mastering core technologies is what Huawei has been striving to achieve. This effort would free Huawei from restrictions on quality, production capacity and price imposed by third-party vendors. It would also give Huawei a similar market position to Apple and Samsung 15 or 20 years late.

Not everyone shares this wisdom, and for many of us, correctly predicting the future is a challenging task. Misjudgments about business trends will lead to miss assessment about the goal element in strategic decisions. Poor decisions on where we can go can also lead to undirected strategic decisions.

Some companies have special group to working on the forecaster of industry development in different regions.

Similar to goal setting, we are not always good at identifying the nature of the problems we encounter. As a Chinese saying goes, the true face of Lushan Mountain is lost to my sight for it is right in this mountain that I reside. In Kodak's case, the company invented digital camera technology, but decided to shelve it because of the impact digital photography would have on the film business. However, the sequestration led to the loss of digital camera business and market share. When executives are insensitive to external changes, they may not notice the development problems facing the company or have a deep understanding of their nature.

The results of strategic decisions can be "confusing" if the decision is incorrect on the question: What are the biggest huddles and challenges we will (or have) encounter(ed) on the way of achieving our development goals? As we described in the previous chapter, a strategy that fails to recognize the major development issues would be a "confusing" strategy.

Similarly, we are not always good at coming up with a good overall guiding ideology for solving the company's growth problems. In the aforementioned battle between Zhu Yuanzhang and Chen Youliang, different people proposed different overall guidelines when faced with a strong enemy from Chen Youliang. Without Liu bowen's thoughts on the battle, perhaps the history of China's Ming dynasty would have been rewritten. In Microsoft's case, it took nearly 10 years to 
understand the characteristics of the Chinese market and come up with a better strategic solution. Without the accumulation of Microsoft's learning, the history of Microsoft in China may be rewritten as well. This brings me to a debate in the field of strategic academics, whether strategy is designed or evolved slowly though learning. The reality is that it is both. The general ideology of the battle between Zhu and Chen is proposed by Liu Bowen and is designed. While the guidelines of Microsoft in the Chinese market in early years are evolved.

Decision makers sometimes make mistakes in the overall guiding principles of strategic decisions. A wrong decision about the "guideline" will lead to a "Utopia" or "Daydreaming" strategy. On the route of company development entwined with thistles and thorns, the long-term goal will be empty-talk without strategic approaches and solutions.

The three circumstances and sub-decisions are embodied in the goal-oriented and problem-oriented strategic decisions. See Figs. 4.2 and 4.3. The figures show that making strategic decision is not an easy task. Any mistake in the three sub-decisions will lead to the incorrectness of a whole strategy.

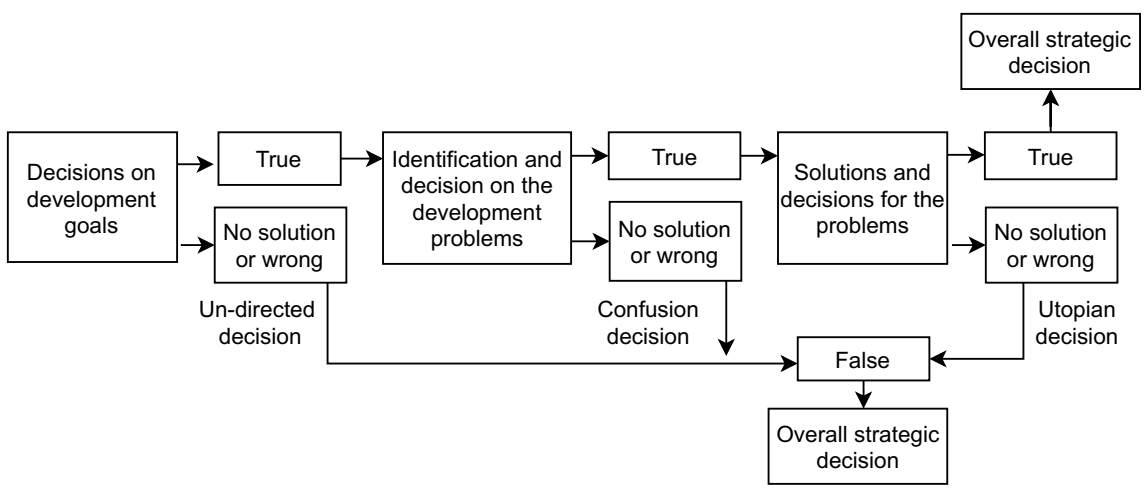

Fig. 4.2 Goal-oriented Strategic Decisions and Possible Mistakes

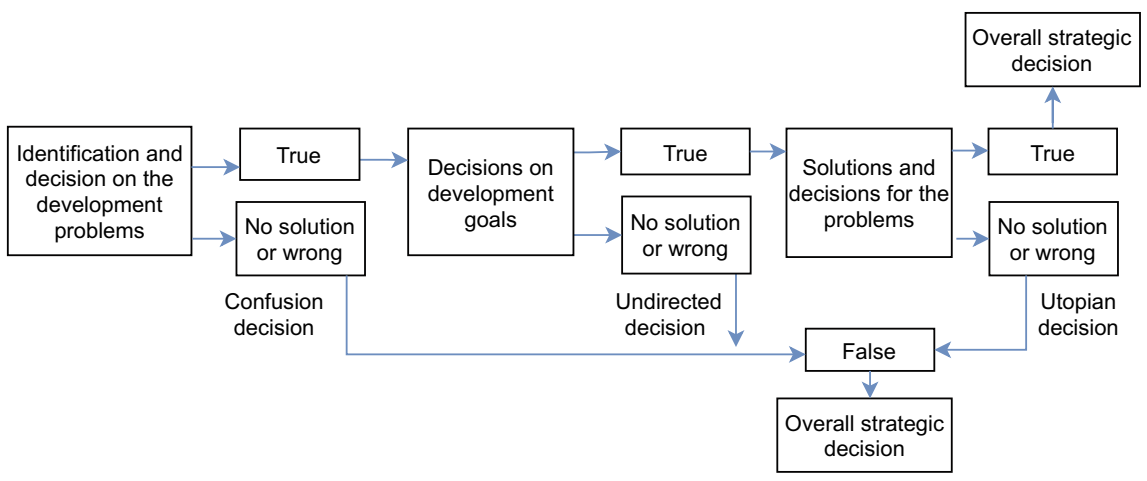

Fig. 4.3 Problem-oriented Strategic Decisions and Possible Mistakes 
Due to the complexity of strategic decisions, some companies have special group or experts working on the forecaster of industry development in different regions. Key indicators in company reports are also periodically reviewed. All these efforts are arming at helping and supporting the right strategic decisions.

\subsection{Conclusions}

To sum up, strategy is an overall guiding ideology that is intended to address major problems encountered in achieving the company's development goals. What is worth noticing further, strategic decision requires getting the hold of organization development directions, forecasting key issues and bringing up general ideology and ideas. A strategic decision involves making decisions on three issues simultaneously. These decisions are all about the development of the company. Getting all three decisions right is not something we can all do, which may explain the complexity and difficulty of strategic decisions.

Any mistake in the decisions will lead to bias and failure. That is to say, a complete strategy is not necessarily a perfect one. Take a car as an example, even if we have all the necessary parts of a car, the customer might not like its color or design, which will result in a drug on the market. Therefore, to make a good strategic decision, the decision-maker not only needs to make three major decisions, but also be equipped with good judgement about future corporate development and high integrations of the three sub-decisions. As strategy concerns with organization future development, large capital investments and the gains and losses in the market competition, therefore, the strategic decision is different from company daily operation decision. It has the characteristics of overall, guidance. Its complexity and difficulty are obvious, which is why many executives feel headache.

As for what biases and mistakes will come up in strategic decision-making, we will delve into the topic in Chap. 7.

Open Access This chapter is licensed under the terms of the Creative Commons Attribution 4.0 International License (http://creativecommons.org/licenses/by/4.0/), which permits use, sharing, adaptation, distribution and reproduction in any medium or format, as long as you give appropriate credit to the original author(s) and the source, provide a link to the Creative Commons license and indicate if changes were made.

The images or other third party material in this chapter are included in the chapter's Creative Commons license, unless indicated otherwise in a credit line to the material. If material is not included in the chapter's Creative Commons license and your intended use is not permitted by statutory regulation or exceeds the permitted use, you will need to obtain permission directly from the copyright holder. 